\title{
The Impact of Intellectual Capital Aspects on Family's Training in Iran's Education
}

\author{
Mohammad Salehi \\ Department of Educational Management, Sari Branch, Islamic Azad University, Sari, Iran \\ Email:M.t_motamed@yahoo.com \\ MT Mo'tamedi Talavaki \\ Department of Educational Management, Sari Branch, Islamic Azad University, Sari, Iran \\ Email: drsalehi@iausari.ac.ir
}

\section{Doi:10.5901/mjss.2015.v6n6s6p138}

\begin{abstract}
The aim of this study was to evaluate intellectual capital aspects on family's training in Iran's education. The research method is descriptive survey and the statistical population are experts of PTA and instructors of family training of the country's education department that were 10526 people. Using cluster random sampling method based on the Cochran formula, 371 subjects were selected. Data collection questionnaires were self-made intellectual capital and family education and its validity was confirmed by experts and its reliability by using Cronbach's alpha coefficient was calculated 0.89 and 0.92. SEM results showed that the dimensions of intellectual capital (human, structural and relational) on the family education (context, content, structure and teaching) has a direct and significant impact and just structural impact on content and training is not significant.
\end{abstract}

Keywords: intellectual capital aspects, family, training, iran, education

\section{Introduction}

Family, first and foremost institution in the history of human civilization and culture is the first school in which man is trained and became familiar with the principles of social life and the understanding with others. Educational role of the family in no time and circumstances cannot be achieved by other factors, the most modern means of communication if they are produced, can't replace family in training, because the relationship between children and parents is unique (scholars, 2012, 13).

Family Education is a process that, according to the general educational facilities exists spontaneously and acts in an organized and systematic way. Because Family and community has a kind of education achieved over time and different experiences of life's ups and downs and in fact not only the family education isn't the training starting point but also is a kind of education in which the experiences of parents about dealing with children is organized according to the new needs of the society (Beh Pajouh, 2011, 12). Education as a social system that interacts increasingly with its environment and interactive environment has to attempt more and adapt itself to rapid changes for fulfilling its aims. Also, the new requirements of today's complex environment with advances in technology is changing and changing every day, leading to the transformation of many topics, including customer and its role in the organization. In such circumstances, what creates value for education is to establish dynamic and continuous communication with families by responding to their needs, desires opinions.

Of course, accomplishing this is subject to the identification and using of organization's capital. In the era of knowledge, what is the success of organizations is knowledge. This intangible asset is known as intellectual capital and its expansion is vital for profit making of organizations. Intellectual capital assets that the organization's ability to create wealth Intellectual capital is an asset that measures the organization's ability to create wealth. This asset can be achieved through the use of properties associated with human resources, organizational performance and obtain external relations. These features creates value in organizations and this value cannot be sold or bought because it's a purely domestic phenomenon. Bontis 1987), defines intellectual capital as three capitals: human, structural and relational (Alam Tabrizi et al., 2008).

Zabihi Atrglh (2013), in a study entitled "The relationship between intellectual capitals with the school administrators making contingency in the city of Sari," concluded that: there is a significant positive relationship between management model making contingency and the dimensions of intellectual capital (human, structural and relational). 
Vaziri et al (2014) in an article entitled "The effectiveness of family education in reduction of symptoms in children with attention deficit hyperactivity disorder" showed that: Family education leads to a reduction in hyperactivity disorder in children and increase the health of the parents. Also parenting skills training to parents not only raise the level of public health but also reduces the symptoms of ADHD in children. Kangarloo et al (2011) in an article entitled "The effect of family education in reducing behavioral problems in children with attention deficit disorder and hyperactivity," concluded that: teaching the basics of behavior to parents can be effective in reduction of disruptive behaviors in children with ADHD. Hosseinpur and December (2010), in a study entitled "Evaluation of the relationship between intellectual capital and social and organizational performance in terms of managers and employees," showed a significant relationship between the dimensions of intellectual capital and organizational performance. Aghdasi and colleagues (2010), in an article entitled 'The Pathology of family education at the education of city of Maku from the perspective of students' parents" showed that the human resources, teaching methods, assessment, and educational content has an impact among on the success of family education and has the greatest impact. Shabani (2009) in a study entitled "The impact of family education on the quality of the relationship between mothers with children in middle school students of Marvdasht" showed that family education plan has a good effect on the mothers and sons, but on the relationship between mothers and daughters the effect is not good. Tabrizi (2009) in an article entitled: "The effect of family education classes in the cultural, educational promotion of children," concluded that family education classes could improve the cultural, educational and academic condition of primary students. Dominique and Moliner (2014) in a study entitled "Family beliefs about inclusive education model" showed that the two groups of families with children with and without disabilities have different beliefs about the (fear and violence, physical and verbal abuse, fear and insecurity) and raising awareness of the families of the inclusive education model lead to improvement of the education of students with disabilities and their social and emotional development. Yildirim and Yildirim (2014) in an article entitled "The effect of family education programs based on the attitude of the parents," found that the average score of families with democratic attitude who participated in the family education program significantly improved, and the results indicates the significant improvement of positive attitudes of parents of children's behavior. Rvdnaz et al (2014) in a study entitled "education for today parents, discipline and fitness to children of tomorrow," revealed that: providing a cognitive and behavioral models for parenting and teaching useful techniques for the education of children and the skills and strategies for communicating with children to parents will improve the behavior of parents with their children with non-violent reactions and eventually leads to the creation of Positive discipline in children. Kalkan and colleagues (2014), in a study entitled "The impact of intellectual capital, innovation and organizational strategy on firm performance" showed that, between intellectual property, innovation, organizational strategy and performance of co-operating in Antalya, Turkey there is a positive and significant relationship. Also intellectual capital has most relevant and organizational strategy has least relevant relationship with corporate performance. Le (2012), in a study entitled "Intellectual Capital and the performance of University" in Taiwan's four public universities achieved that; the universities pay more attention to financial resources rather than teaching and research interests. Also IC is an effective way to improve strategies and helps managers to improve their performances. Colby and Nlvr (2012) in an article entitled "The attitude of parents towards their children before and after the education of parents' showed that family education has a positive and significant impact on the attitudes of parents towards their children. Fryha Dewey and Sophie (2012), in a study entitled "The relationship between intellectual capital and organizational performance" in 144 Malaysian companies, showed that there is a positive relationship between intellectual capital and organizational performance. Also the capital of relationship is most effective and is followed by spiritual capital, structural capital and human capital. Samuelson (2010) in an article entitled "Best Practices for family education and support programs" showed that the components of the program content, time schedule, program performance, teaching methods, ecological landscape, culture compatible, teacher characteristics, development of national internet site of family education is are effective for development of family education programs and should be taken into consideration.

Terms of today's world, due to the rapid scientific, technical, cultural, political, social and economic developments on one hand and problems of the families on the other hand, failure to keep pace with these developments, and with particular problems in industrialized societies and urban life, especially of occupational and absence of parents in families the importance and necessity of additional training is considered more and more. Most studies emphasize the fact that children should be trained by the comprehensive, organized and pre-planned education. While the education system of Iran doesn't have any comprehensive instructions, clear strategies and specific model, for family education and only by providing the internal letters and determination of topics for the workshops more important than these political developments has a profound impact on the process. Thus, according to presentations about intellectual capital and family education, main question is: "Does the dimensions of intellectual capital have an impact on family training in Iran's education?" 


\section{Methodology}

This study, in terms of purpose and method is a description survey and the statistical population are experts of PTA and instructors of family training of the country's education department that were 10526 people. Using cluster random sampling method based on the Cochran formula, 371 subjects were selected. For data collection questionnaire with 24 questions, in three dimensions (human, structural and relational) model based on Bontis (1998) was built and family education questionnaire with 80 questions, in four dimensions (context, content, structure and education) and fifteen factors (culture and common values, goals, strategies, competencies, human resources, business processes, relations, educational technology, organization, planning, funding and facilities, monitoring and evaluation, behavioral, social, educational and moral) was used. Tool content and face validity was confirmed by experts and its reliability using the Cronbach alpha coefficient was calculated IC 0.89 and 0.92 of family education that is statistically confirmed. Structural equation modeling was used to analyze the data from the test.

\section{Results}

SEM was used to evaluate the hypothesis of this study and the results with the integration model and balanced based on direct and indirect relationships between variables using LISREL software in Figures 1 and 2 and Table 1 is presented.
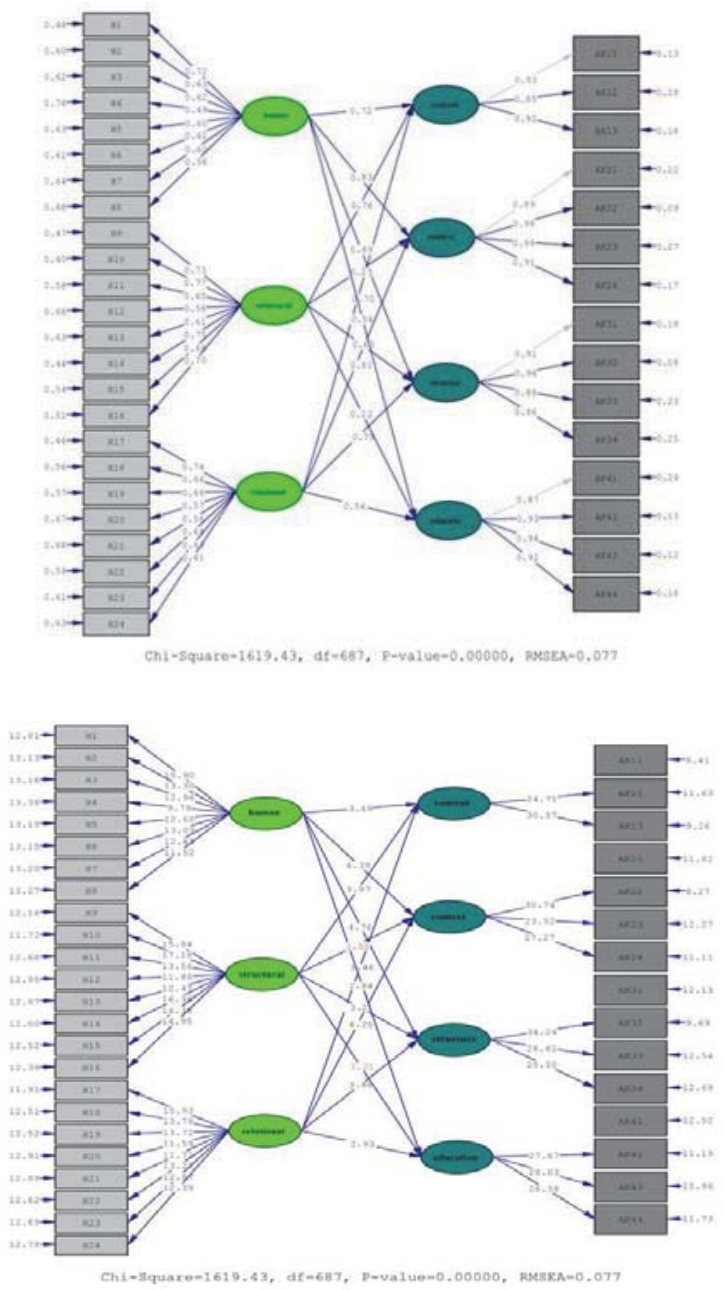
Table 1. The results of the measurement results in a significant level of $05 / 0$

\begin{tabular}{|l|c|c|l|l|l|}
\hline Test result & Standard rate & t-statistics & Model Assumptions & Row \\
\hline confirmed & 0.72 & 3.69 & Human aspect has a significant impact on content aspect in family education. & 1 \\
\hline confirmed & 0.83 & 4.39 & Human aspect has a significant impact on context aspect in family education. & 2 \\
\hline confirmed & 0.89 & 4.76 & Human aspect has a significant impact on structure aspect in family education. & 3 \\
\hline confirmed & 0.54 & 2.84 & Human aspect has a significant impact on teaching aspect in family education.. & 4 \\
\hline confirmed & 0.76 & 3.97 & Structural aspect has a significant impact on content aspect in family education. & 5 \\
\hline rejected & 0.25 & 1.51 & Structural aspect doesn't have a significant impact on context aspect in family education. & 6 \\
\hline confirmed & 0.63 & 3.21 & Structural aspect has a significant impact on structure aspect in family education.. & 7 \\
\hline Rejected & 0.22 & 1.21 & Structural aspect doesn't have a significant impact on teaching aspect in family education. & 8 \\
\hline Confirmed & 0.70 & 3.48 & Relation aspect has a significant impact on content aspect in family education.. & 9 \\
\hline Confirmed & 0.81 & 4.25 & Relation aspect has a significant impact on context aspect in family education.. & 10 \\
\hline confirmed & 0.79 & 3.88 & Relation aspect has a significant impact on structure aspect in family education. & 11 \\
\hline confirmed & 0.56 & 2.93 & Relation aspect has a significant impact on teaching aspect in family education & 12 \\
\hline$X^{2}=1619 / 43$ df=687 RMSEA=0/077 CFI=0/93 IFI=0/91 NNFI=0/95 Fl=0/91 GFI=0/90 P < 0.05 & \\
\hline
\end{tabular}

The results in Figures 1 and 2 and Table 1 show that, the amount of Chi- square is 43/1619=x2 and $687=\mathrm{df}$ and the estimate is $357 / 2=x 2 / d f$. Because in this index less than 3 means that the model is good, so the model is chosen correctly. Also Also root mean square error of approximation is calculated 077/0 = RMSEA that in this index Less than 08/0 expresses the suitability of the model. Parameters of suitability of the model includes: Comparative fit index of 93/0 = $\mathrm{CFI}$, comparative fit index of $91 / 0=\mathrm{RFI}$ and goodness of fit index $90 / 0=\mathrm{GFI}$ is. The above factors, high levels of 9.0 indicates a perfect fit model. Therefore it can be said that the proposed model was appropriate, and the relationship between variables are significant. Also according to beta coefficient and t-statistic that was more than 96/1 the dimensions of intellectual capital (human, structural and relational) has a direct and significant impact on the family education (context, content, structure and teaching) and only impact of structure on context is $t=1.51$ and on the training $t=1.21$ was calculated as less than 1.96 , so isn't significant.

\section{Conclusion}

Today, for educating children properly by families and raising children that are useful to society, they need an understanding beyond the folk understanding that can be driven from life experience. For the same purpose and to improve and changes the families' knowledge, attitude and behavior toward their children, better parenting programs such as family education is included in the education systems of most countries such as Iran. However, at the present time due to current changes, it is vital for organizations and communities to be aware of their intellectual capital, because the organization or society that isn't able to identify and solve their intellectual capital, cannot preserve their competitive advantage in the national and international arena. Therefore, the effect of intellectual capital dimension on family education in Iran's education is discussed. The results showed that the dimensions of intellectual capital (human, structural and relational) has a direct and significant impact on the family education (context, content, structure and teaching) and just structural impact on content and training is not significant. These research results are in line with Tabrizi (2011), Kalkan and colleagues (2014) and Le (2012). It is suggested that managers and directors of education programs should promote intellectual capital of the organization by a coherent scientific planning and as a result advance family education.

\section{References}

Beh Pazhoh, Ahmad. (2012). considering the importance of family education and five principles to communicate with teenagers. Monthly training-education link, No. 399, pp. 16-11.

Alam Tabriz, Akbar Haji Babaei, Ali and Rajabifard Iman. (2009). Intellectual capital. Tehran: Iran Industrial Research and Training Center.

Alamin, Zahra. (2013). the need for providing family education classes in schools. Monthly training-education link, No. 409, Ss43-38.

Kangarooha, M, Lotfi Kashani, FarahVazirie, Sh. (2012). The effect of family education in reducing behavioral problems in children with attention deficit disorder and hyperactivity. Journal of Medical Sciences, Islamic Azad University, the twenty-second period, No. 3, Fall, pp. 220-216.

Zabihi Atrglh, Sima. (12014). the relationship between intellectual capital with the school administrators making contingency decisions in the city of Sari. MA thesis in Educational Management. University of Sari. 
Hanifi, F; Heidari tafreshi, Gholam Hossein Sohani, Atefeh. (2012). the impact of family education programs to strengthen critical thinking among elementary students in Tehran. Journal of Research in Educational Management, Issue 1, Ss56-39.

Hosseinpur, Davood and Azar, M. (2010). Examine the relationship between intellectual capital and social and organizational performance in terms of managers and employees. Journal of Management Development and Transformation, No. 7, Ss29-19.

Aghdasi, Ali Naqi, Farid, and Bayramzadeh A. Humira. (2010). Pathology of family education at the Education of Makoo from the perspective of parents of students in 2010. Journal of Woman and Family Studies, Issue 14, Ss64-43.

Shabani, HR. (2011). The impact of family education on the quality of the relationship between mothers with children in middle school students of Marvdasht in the 89-88 school year. Master thesis, Islamic Azad University of Marvdasht.

Tabrizi, Gh. (2011). The effect of family education classes in cultural, spritual and educational promotion in children. Monthly trainingeducation link, No. 377, pp. 21-18.

Bontis, N. (1998). Intellectual capital: an exploratory study that develops measures and models. Management decision, 36(2), 63-76.

Celebi Oncu, Elif \& Esra Unluer. (2012). Parent s' Attitude towards Their Children before and After Parental Education. Procedia - Social and Behavioral Sciences, 46, $5933-5936$.

Dewi Fariha, A., \& Sofian, S. (2012). The Relationship between intellectual capital and corporate performance. Procedia- Social and Behavioral Sciences, 40, 537-541.

Doménech, Ana \& Odet Moliner. (2014). Families Beliefs about Inclusive Education Model. 5th World Conference on Educational Sciences - WCES. Procedia - Social and Behavioral Sciences, 116, 3286 - 3291.

Kalkan, K., Çetinkaya Bozkurt, O., \& Arman, M. (2014). The impacts of intellectual capital, innovation and organizational strategy on firm performance. Procedia - Social and Behavioral Sciences, 150, $700-707$.

Lu, W-M. (2012). Intellectual capital and university performance in Taiwan. Economic Modelling, 29, 1081-1089.

Bontis, N. (1998). Intellectual capital: an exploratory study that develops measures and models. Management decision, 36(2), 63-76.

Celebi Oncu, Elif \& Esra Unluer. (2012). Parent s' Attitude towards Their Children Before and After Parental Education. Procedia - Social and Behavioral Sciences, 46, 5933 - 5936.

Dewi Fariha, A., \& Sofian, S. (2012). The Relationship between intellectual capital and corporate performance. Procedia- Social and Behavioral Sciences, 40, 537-541.

Doménech, Ana \& Odet Moliner. (2014). Families Beliefs about Inclusive Education Model. 5th World Conference on Educational Sciences - WCES. Procedia - Social and Behavioral Sciences, 116, 3286 - 3291.

Kalkan, K., Çetinkaya Bozkurt, O., \& Arman, M. (2014). The impacts of intellectual capital, innovation and organizational strategy on firm performance. Procedia - Social and Behavioral Sciences, 150, 700 - 707.

Lu, W-M. (2012). Intellectual capital and university performance in Taiwan. Economic Modelling, 29, 1081-1089. 